\title{
Keynes y la crisis financiera actual
}

\author{
Título: Keynes y la crisis financiera actual. \\ Autor: Antonio Torrero Mañas \\ Edición: Madrid, Marcial Pons, 2013,180 págs. \\ Manuel MARTíN RODRÍGUEZ
Universidad de Granada
}

Desde la publicación de su importante libro La obra de John Maynard Keynes y su visión del mundo financiero (1998), Antonio Torrero ha venido estando interesado fundamentalmente por las finanzas internacionales, por su evolución y por la propia evolución del pensamiento económico en este campo desde 1920, fecha en que comienzan las grandes aportaciones analíticas del gran economista de Cambridge, hasta nuestros días. Si hasta que estalló la actual crisis financiera estuvo interesado principalmente por la deriva que estaban tomando las finanzas hacia una progresiva inestabilidad, desde 2008 sus esfuerzos se han centrado en lo que desde el primer momento él intuyó como una perturbación de largo alcance, llamada a una renovación de la ciencia económica de similar calado a la que supuso la Teoría General de Keynes siete años después de la crisis de 1929. Fruto de esta preocupación han sido seis espléndidos libros 1 , breves todos ellos, que constituyen un modelo de solidez, de consistencia interna y de continuidad en el análisis de lo que ha venido ocurriendo en los seis últimos años, casi al borde ya del tiempo que se concedió Keynes para su definitivo análisis de la crisis de 1929.

Keynes y la crisis financiera actual, el libro que reseñamos aquí, se publicó a principios de 2013. Consta de tres trabajos breves, en los que se recogen sendas intervenciones de su autor en diferentes ámbitos académicos, y uno de mayor extensión, que da título al libro. Como en toda su obra anterior, la incertidumbre esencial keynesiana juega un papel fundamental en este libro de Torrero. Para reducir la fragilidad de los sistemas que se deriva de ella, resulta absolutamente necesario para él un cierto grado de implicación del Estado en la economía. Y como la incertidumbre es mayor en el largo plazo, la intervención debe ser mayor en los mercados financieros en los que se negocian productos de inversión, la actividad económica en la que juegan un papel más importante el tiempo y las expectativas.

\footnotetext{
${ }^{1}$ Además del libro que se reseña, los demás títulos son: Internacionalización de las Bolsas y de las Finanzas. Funcionamiento del patrón oro y la moneda única europea (2001); La Burbuja Especulativa y la Crisis Económica de Japón (2003); Crisis Financieras. Enseñanzas de cinco episodios (2006); Revolución en las Finanzas. Los grandes cambios en las ideas. Represión y Liberalización Financiera ((2008); La crisis financiera internacional. Cuarto año (2011); La crisis financiera internacional y sus efectos sobre la empresa española (2011); y España en el laberinto del euro (2013).
} 
Consecuente con ello, adoptando el punto de vista de Minsky 2 , uno de los últimos keynesianos fundamentalistas y también uno de sus economistas preferidos, Torrero sostiene que aún cuando fuera necesario renunciar a un cierto grado de eficiencia en el mercado, o a una eventual mayor tasa de crecimiento económico, tal intervención debería aceptarse a fin de contener la incertidumbre de los mercados financieros, que amenaza la democracia y la sociedad abierta y liberal.

A partir esta idea fundamental, el profesor Torrero, bien provisto de todo el arsenal analítico financiero post-keynesiano, resulta totalmente previsible. Para él, la capacidad de la ciencia económica para acertar en sus previsiones y pronósticos es muy limitada, pero, en cambio, puede llegar a "detectar desequilibrios acumulativos con tendencias insostenibles". Y, por ello, lo que debería hacer es tratar de descubrir ese tipo de situaciones y aconsejar medidas para frenar excesos que, de mantenerse, terminarían de forma abrupta. Es exactamente la posición contraria a la de Greenspan y el propio Bernanke, antes de la crisis, que aunque admitían que las burbujas pueden causar estragos económicos, consideraban que era imposible predecirlas con suficiente anticipación, por lo que ni la regulación ni la política monetaria debían intervenir hasta que se produjeran realmente.

En su libro, Torrero señala como significativo que en la respuesta que diera Keynes en 1937 a los críticos de su Teoría General, pusiera el énfasis en la incertidumbre como clave diferencial de su aportación. En los años setentas, a partir de obra de Eugene Fama, esta idea se olvidaría y acabaría imponiéndose la hipótesis de los mercados eficientes (EMH), por la que los mercados financieros siempre aciertan y, por tanto, por el propio bien de la economía en su conjunto, debía dejarse que actuaran como antídoto ante cualquier posible inestabilidad. Después, en los ochentas, la creencia de que podían construirse modelos objetivos de medición de riesgos terminaría consolidando un paradigma en las antípodas del capítulo XII de la Teoría General. Para Torrero, la crisis financiera actual tendría mucho que ver con esta evolución del pensamiento económico dominante.

Con todo ello, Torrero reconstruye el acervo a duras penas conservado por los post-keynesianos fundamentalistas: Shackle, Minsky, Stiglitz y Davidson. Para él, la crisis actual habría venido a dar la razón a este grupo minoritario de economistas, al poner en evidencia los cinco puntos esenciales del paradigma vigente hasta el momento de producirse: la creencia en la capacidad de cuantificar el riesgo, las virtudes de la liberalización financiera, las ventajas de los mercados sobre la intermediación bancaria, la conveniencia de la internalización de las finanzas y la contribución de éstas al crecimiento económico. Como él mismo apunta, citando a Rodrik $_{3}$, en el trilema político fundamental de la economía mundial no pueden perseguirse simultáneamente democracia, autonomía nacional y globalización económica. Y como en la situación actual el eslabón más débil es éste último, resulta

\footnotetext{
${ }^{2}$ Minsky, H.P. (1996): "Uncertainty and the Institutional Structure of Capitalist Economicss", Jounal of Economic Issues, Vol. XXX, num. 2, june.

${ }^{3}$ Rodrik, D. (2011): La paradoja de la globalización. La democracia y el futuro de la economía mundial, Barcelona: Antoni Bosch.
} 
necesaria una regulación de las finanzas internacionales que proteja de la incertidumbre y que permita cosechar al menos los éxitos del diseño Keynes-White de Bretton Woods.

Esto no significa, sin embargo, para Torrero, que se esté cerca de sustituir el paradigma que ha estado vigente hasta la crisis de 2007. Las recientes apostasías de Mankiw y del propio Greenspan no son suficientes y, en todo caso, no van en la dirección adecuada. Como Justin Fox 4 , el autor de The Mith of the Rational Market (2009), Torrero se muestra pesimista respecto a que vayamos a disponer pronto de una obra similar a la Teoría General en relación con la presente crisis. Para que esto ocurra, habrá que abandonar la rigidez e irrealismo del paradigma todavía vigente para regresar de nuevo, con humildad, a la naturaleza esencialmente incierta del futuro y a la asunción del componente animal spirits de la conducta humana, que han resucitado recientemente, entre otros, Akerlof y Shiller $_{5}$. Y no bastará sólo con incorporar variables e hipótesis financieras más realistas a los actuales modelos macroeconómicos. En palabras de Torrero: "La comprensión de la realidad exige volcar la atención en los aspectos históricos e institucionales que, mucho me temo, no constituyen el núcleo de la inquietud actual de la profesión, aunque la crisis esté forzando a revisar las ideas predominantes". Es lo mismo que ha dicho el propio Shiller en un reciente artículo de gran impacto, en el que ha insistido en que a la enseñanza de la economía deben incorporarse las aportaciones de otras ciencias sociales, como la psicología, la sociología, la ciencia política, la antropología y la historia ${ }_{6}$. La gran cuestión es si podrá la ciencia económica superar este nuevo reto.

\footnotetext{
${ }^{4}$ Fox, Justin, "What We've Learned from the Financial Crisis", Harvard Business Review, November 2013:94-101

${ }^{5}$ Akerlof, G., and R. Shiller (2009): Animal Spirits: How human psychology drives the economy and why it matters for global capitalism, Princeton, N. J.: Princeton University Press

${ }^{6}$ Shiller, Robert J. (2010): "How Should the Financial Crisis Change How We Teach Economics?", The Journal of Economic Education, 41 (4), 403-409, 2010.
} 